\title{
Novel clades of soil biphenyl degraders revealed by integrating isotope probing, multi-omics, and single-cell analyses
}

\author{
Song-Can Chen $\mathbb{1}^{1} \cdot$ Rohit Budhraja ${ }^{1} \cdot$ Lorenz Adrian $\mathbb{D}^{2,3} \cdot$ Federica Calabrese $\mathbb{D}^{1} \cdot$ Hryhoriy Stryhanyuk ${ }^{1} \cdot$ \\ Niculina Musat $\mathbb{D}^{1} \cdot$ Hans-Hermann Richnow ${ }^{1} \cdot$ Gui-Lan Duan ${ }^{4} \cdot$ Yong-Guan Zhu $\mathbb{C}^{4,5} \cdot$ Florin Musat $\mathbb{B}^{1}$
}

Received: 20 February 2021 / Revised: 12 May 2021 / Accepted: 21 May 2021 / Published online: 11 June 2021

(c) The Author(s) 2021. This article is published with open access

\begin{abstract}
Most microorganisms in the biosphere remain uncultured and poorly characterized. Although the surge in genome sequences has enabled insights into the genetic and metabolic properties of uncultured microorganisms, their physiology and ecological roles cannot be determined without direct probing of their activities in natural habitats. Here we employed an experimental framework coupling genome reconstruction and activity assays to characterize the largely uncultured microorganisms responsible for aerobic biodegradation of biphenyl as a proxy for a large class of environmental pollutants, polychlorinated biphenyls. We used ${ }^{13} \mathrm{C}$-labeled biphenyl in contaminated soils and traced the flow of pollutant-derived carbon into active cells using single-cell analyses and protein-stable isotope probing. The detection of ${ }^{13} \mathrm{C}$-enriched proteins linked biphenyl biodegradation to the uncultured Alphaproteobacteria clade UBA11222, which we found to host a distinctive biphenyl dioxygenase gene widely retrieved from contaminated environments. The same approach indicated the capacity of Azoarcus species to oxidize biphenyl and suggested similar metabolic abilities for species of Rugosibacter. Biphenyl oxidation would thus represent formerly unrecognized ecological functions of both genera. The quantitative role of these microorganisms in pollutant degradation was resolved using single-cell-based uptake measurements. Our strategy advances our understanding of microbially mediated biodegradation processes and has general application potential for elucidating the ecological roles of uncultured microorganisms in their natural habitats.
\end{abstract}

Supplementary information The online version contains supplementary material available at https://doi.org/10.1038/s41396021-01022-9.

Yong-Guan Zhu

ygzhu@rcees.ac.cn

$\triangle$ Florin Musat

florin.musat@ufz.de

1 Department of Isotope Biogeochemistry, Helmholtz Centre for Environmental Research-UFZ, 04318 Leipzig, Germany

2 Department Environmental Biotechnology, Helmholtz Centre for Environmental Research-UFZ, Leipzig, Germany

3 Chair of Geobiotechnology, Technische Universität Berlin, 13355 Berlin, Germany

4 State Key Lab of Urban and Regional Ecology, Research Center for Eco-Environmental Sciences, Chinese Academy of Sciences, 100085 Beijing, China

5 Key Lab of Urban Environment and Health, Institute of Urban Environment, Chinese Academy of Sciences, 361021 Xiamen, China

\section{Introduction}

One of the grand challenges of microbial ecology and ecosystem science is to link microbial community structure to microbial functional traits underpinning key ecological processes $[1,2]$. To date, the physiological and ecological functions of most microorganisms in natural habitats remain poorly characterized particularly due to their recalcitrance to cultivation [3,4]. To some extent, the need to cultivate individual taxa has been overcome by recent advances in environmental metagenomic sequencing and computational approaches. This enabled community-level genome reconstruction from a wide range of ecosystems, shedding new insights into phylogenetic identity and metabolic potential of numerous uncultured lineages [5-9]. Consequently, the physiology and ecological roles of uncultured bacteria and archaea have been lately inferred mostly from reconstructed genomes. However, these genome-driven discoveries relied strongly on the predictive understanding of genes and metabolic pathways, which do not always reflect actual functions carried out by microorganisms in their natural 
habitats. Thus, it became apparent that experimental evidence to support genome-based predictions by direct detection and quantification of function is needed to properly understand the role of uncultured microorganisms in ecologically significant biogeochemical processes $[2,4,10,11]$.

A prominent, microbially mediated environmental process is the biodegradation of widespread, persistent organic pollutants like polychlorinated biphenyls (PCBs), which have broad consequences for human health and ecosystem functioning [12, 13]. The identity of microorganisms involved in such processes in various environments has been extensively investigated by both culture-dependent and culture-independent methods. The formerly provided insights into the biochemical basis of pollutant activation and downstream transformation in pure cultures [14-17]. The latter targeted active pollutant-metabolizing microorganisms within natural microbial communities, such as those inhabiting PCB-contaminated soils and sediments, through substrate-specific labeling of their DNA by stable isotope probing (SIP). Sequence analysis of marker genes (i.e., 16S rRNA gene) retrieved from labeled fractions of community DNA revealed the phylogenetic identity of metabolically active populations [18-23]. These SIP-based gene surveys indicated that pollutant removal in contaminated environments was mostly achieved by uncultured microorganisms; only a small fraction of these are represented by closely related isolates or genomes [24-26]. Thus, there is remarkably little reliable information about the full genetic potential and taxon-specific metabolism of the ecologically relevant degraders. Furthermore, DNA-based SIP provided only a qualitative link between phylogenetic identity and biodegradation activity, whereas direct quantification of metabolic rate and cellular abundance has never been obtained for pollutant degraders in real-world habitats like soils.

Here we selected biphenyl as a model compound to document metabolic activities and genomic makeup of biodegradative microbial populations of PCB-impacted soils. Biphenyl has often been used as a proxy to investigate the biodegradation of PCBs since many PCB congeners can be co-metabolized by biphenyl-oxidizing microorganisms via the same oxidation pathways [27, 28]. The capacity of the soil microbial communities to oxidize biphenyl was initially assessed using cultivation approaches. We then coupled stable isotope probing with nanoscale secondary ion mass spectrometry (nanoSIMS) to image and quantify biphenyl assimilation by individual microbial cells. The phylogenetic identity of biphenyl oxidizers was resolved using metaproteomics-SIP based on metagenomic databases constructed for each soil type investigated. Moreover, for the identified microorganisms, we used the metagenome-assembled genomes (MAGs) to reconstruct the complete metabolic pathways involved in biphenyl oxidization.

\section{Materials and methods}

\section{Chemicals}

The chemicals used include ${ }^{13} \mathrm{C}$-biphenyl $\left(99\right.$ atom $\%{ }^{13} \mathrm{C}$; Cambridge Isotope Laboratories, Inc., USA), unlabeled biphenyl (Sigma-Aldrich), nuclease-free water (ThermoFisher Scientific), dichloromethane (Sigma-Aldrich), sodium cacodylate buffer (Electron Microscopy Sciences, USA), and Nycodenz (Progen).

\section{Soil samples}

The four soil samples investigated in this study were collected from Taizhou, Zhejiang Province, China, and were denoted as soil A (river sediment; $28^{\circ} 32^{\prime} 19^{\prime \prime} \mathrm{N}, 121^{\circ} 22^{\prime} 41^{\prime \prime} \mathrm{E}$ ), soil B (paddy soil; $28^{\circ} 32^{\prime} 28^{\prime \prime} \mathrm{N}, 121^{\circ} 22^{\prime} 15^{\prime \prime} \mathrm{E}$ ), soil C (river sediment; $28^{\circ} 37^{\prime} 13^{\prime \prime} \mathrm{N}, 121^{\circ} 24^{\prime} 54^{\prime} \mathrm{E}$ ), and soil D (upland soil; $\left.28^{\circ} 30^{\prime} 32^{\prime \prime} \mathrm{N}, 121^{\circ} 21^{\prime} 49^{\prime \prime} \mathrm{E}\right)$, respectively. The sampling sites were historically contaminated with PCBs at concentrations of $0.03-5 \mathrm{mg} \mathrm{kg}^{-1}$ (Supplementary Table 1). The samples were stored at $4{ }^{\circ} \mathrm{C}$ until analysis or use for incubation experiments. A diagram summarizing our main experimental workflow is presented in Supplementary Fig. 1.

\section{Establishing biphenyl-degrading enrichment cultures}

Incubations with biphenyl were set up in $150 \mathrm{ml}$ conical flasks provided with $30 \mathrm{ml}$ aerobic, mineral freshwater medium [29, 30], and $5 \mathrm{~g}$ of soil as inoculum. Crystals of biphenyl (approx. $20 \mathrm{mg}$ per flask) were added as the sole carbon and energy source. The flasks were sealed with cotton stoppers to permit the free passage of oxygen. Incubation was done at $28{ }^{\circ} \mathrm{C}$ in the dark with gentle horizontal shaking $(120 \mathrm{rpm})$. Controls without the addition of biphenyl were prepared similarly and incubated under the same conditions. Biphenyl-dependent growth was monitored by observing changes of turbidity and by microscopic examinations. Sediment-free enrichment cultures were obtained after five subsequent transfers into fresh culture media with $10 \%$ inoculum each. Enrichment cultures were further maintained by inoculating $10 \%$ volume of grown cultures to fresh-water medium every three days. Growth experiments with the enrichment cultures were prepared under the same conditions as described above. Growth was monitored by measuring the OD at $\lambda=600 \mathrm{~nm}$ every four hours by subsampling $0.5 \mathrm{ml}$ of culture. Inoculated medium without biphenyl was used as a control. 


\section{DNA extraction and community sequencing}

DNA was extracted from $0.5 \mathrm{~g}$ soil as described previously [31]. The soil samples were suspended in $1.35 \mathrm{ml}$ extraction buffer (100 mM Tris-HCl, $100 \mathrm{mM}$ sodium EDTA, $100 \mathrm{mM}$ sodium phosphate, $1.5 \mathrm{M} \mathrm{NaCl}, 1 \% \mathrm{CTAB}, \mathrm{pH} 8.0$ ) and lysed via three cycles of freezing and thawing at $-196^{\circ} \mathrm{C}$ and $37^{\circ} \mathrm{C}$, respectively. The resulting lysates were further incubated with $10 \mathrm{mg} \mathrm{ml}^{-1}$ proteinase $\mathrm{K}$ at $37{ }^{\circ} \mathrm{C}$ for $30 \mathrm{~min}$ and with $20 \%$ SDS at $65^{\circ} \mathrm{C}$ for $1 \mathrm{~h}$, followed by $10 \mathrm{~min}$ centrifugation at $12{ }^{\circ} \mathrm{C}, 15,000 \mathrm{rpm}(21,130 \times \mathrm{g})$. The resulting supernatant was extracted with an equal volume of chloroform:isoamyl alcohol $(24: 1, \mathrm{v} / \mathrm{v})$. Nucleic acids were precipitated with isopropanol (0.6 volume, $1 \mathrm{~h}$ at room temperature). The yielded DNA was dissolved in $50 \mu \mathrm{l}$ nuclease-free water and stored at $-20^{\circ} \mathrm{C}$ before use. For DNA extraction from biphenyl-degrading enrichments, the same procedure was applied to cells harvested from $20 \mathrm{ml}$ grown cultures. The V3-V5 region of bacterial $16 \mathrm{~S}$ rRNA genes was amplified using primers 341F (5'-CCTAC GGGNGGCWGCAG-3') and 785 R (5'-GACTACHVGGGT ATCTAATCC-3') and sequenced on MiSeq (Illumina) V3 platform $(2 \times 300$ cycles). After removal of adapters and primers, the paired-end reads were joined using BBMap v38.51 (https://sourceforge.net/projects/bbmap/) and processed using the SilvaNGS pipeline $[32,33]$. Operational taxonomic units (OTUs) were clustered at 98\% sequence identity level and classified taxonomically using the Silva v.132 databases. The OTU table was downloaded from SilvaNGS and rarefied to minimum sequencing depth across samples $(36,000$ for soils; 10,000 for enrichments). Alpha diversity indices, including the Shannon, Chaol, Simpson, and Simpson's evenness measure E, were calculated using the Vegan R package (Supplementary Table 2). Beta diversity was assessed using the capscale function in the Phyloseq $\mathrm{R}$ package based on Bray-Curtis dissimilarity (Supplementary Fig. 2).

\section{Stable isotope probing in slurry microcosms}

To determine the biphenyl-degrading capacity of the original soil samples, slurry microcosms were established in 20 -ml sealed serum vials. To enhance biphenyl bioavailability, unlabeled or ${ }^{13} \mathrm{C}$-labeled biphenyl was dissolved in dichloromethane (DCM) at a concentration of $20 \mathrm{mg} / \mathrm{ml}$. A volume of $0.1 \mathrm{ml}$ of this solution was added per vial $(2 \mathrm{mg}$ net biphenyl per vial); the DCM was thereafter completely evaporated, leaving biphenyl crystals homogeneously distributed on the inner wall of vials. Soil slurries were prepared for each soil type by mixing soil samples with freshwater medium to reach $\sim 75 \%(\mathrm{v} / \mathrm{v})$ pore-water content. Vials were thereafter supplied with $3 \mathrm{ml}$ slurry, sealed with rubber stoppers, and incubated in the dark at $28^{\circ} \mathrm{C}$ with continuous shaking $(120 \mathrm{rpm})$. For each soil type, a total of 14 replicate microcosms were prepared, of which 7 contained unlabeled biphenyl and 7 contained ${ }^{13} \mathrm{C}$-biphenyl. Two replicates were sacrificed for each soil type and substrate combination, at seven time points $(0,2,4,8,24,48$, and $96 \mathrm{~h}$ of incubation). The headspace of the microcosm was collected to determine the carbon isotope composition of $\mathrm{CO}_{2}$ [34]. The slurries were either frozen $\left(-20^{\circ} \mathrm{C}\right)$ for molecular biological analysis or fixed for nanoSIMS analysis. For sample fixation, the sediments were incubated with 3\% paraformaldehyde (final concentration) for $1 \mathrm{~h}$ at room temperature, washed two times with $1 \times \mathrm{PBS}$, and stored in $1 \times$ PBS:ethanol $(1: 1, \mathrm{v} / \mathrm{v})$ at $-20^{\circ} \mathrm{C}$.

\section{Soil cell extraction and nanoSIMS analysis}

To detach cells from soil particles for subsequent nanoSIMS analyses, we used established protocols based on alternating mild chemicals (using tensioactive compounds) and mechanical treatments [35]. In brief, $200 \mu$ l of PFA-fixed sediment was mixed with $700 \mu \mathrm{l}$ TE buffer $(10 \mathrm{mM}$ Tris$\mathrm{HCl}, 5 \mathrm{mM}$ EDTA, pH 9.0) and $100 \mu \mathrm{l}$ pyrophosphate $\left(100 \mathrm{mM}\right.$ ), followed by incubation at $55^{\circ} \mathrm{C}$ for $5 \mathrm{~min}$ (water bath of a histological microwave oven operated at $200 \mathrm{~W}$; Microwave Research and Application Inc., Laurel, MD, USA). The samples were then amended with $1 \mu$ Tween 80 and mixed for $15 \mathrm{~min}$ at room temperature on a benchtop vortex (level 3, $1060 \mathrm{rpm}$, Grant-bio). Cells were thereafter separated from soil particles using established Nycodenz density centrifugation protocols [35]. Each sample was transferred to a $50 \mathrm{ml}$ Falcon tube containing $22.5 \mathrm{ml} 1 \times$ PBS and $2.5 \mathrm{ml}$ pyrophosphate. A volume of $2 \mathrm{ml} \mathrm{Nyco-}$ denz solution $(1.426 \mathrm{~g} / \mathrm{ml}, 80 \% \mathrm{w} / \mathrm{v})$ was slowly added to the bottom of the Falcon tube using $10 \mathrm{ml}$ pipette tips to avoid mixing of Nycodenz and slurries. High-speed centrifugation $\left(1.5 \mathrm{~h}, 16,000 \times g, 4{ }^{\circ} \mathrm{C}\right.$; ROTINA 380R, Hettich) was applied to separate cells from soil particles. Cellcontaining water phase (approx. $25 \mathrm{ml}$ ) on the top of the Nycodenz layer was carefully collected in clean $50 \mathrm{ml}$ Falcon tubes.

For nanoSIMS analyses, $10 \mathrm{ml}$ of supernatant recovered from the Nycodenz extraction procedure was filtered on gold-palladium-coated polycarbonate filters $(0.22 \mu \mathrm{m}$ pore size). The samples were rinsed twice with sodium cacodylate buffer (0.2 M, pH 7.4; Electron Microscopy Sciences), dehydrated in an ethanol series prepared in the same buffer (30, 50, 70, 80, 90, 96, and 100\%), and dried for 20 exchange cycles using critical point drying machine (Critical Point Dryer, LEICA EM CPD300). Filter pieces of $10 \mathrm{~mm}$ in diameter were cut using a punching tool and placed on the sample holder of a nanoSIMS-50L instrument (CAMECA, AMETEK). NanoSIMS analyses were performed in negative extraction mode using $\mathrm{Cs}^{+}$as the primary ion source. Prior to measurements, $100 \times 100 \mu^{2}$ areas were pre-implanted with $16 \mathrm{keV}$ cesium $\left(\mathrm{Cs}^{+}\right)$primary ion beam at $200 \mathrm{pA}$ for 
$10 \mathrm{~min}$. Fields of view of $25 \times 25 \mu \mathrm{m}^{2}$ were analyzed with a 3 pA primary ion beam, scanning at $512 \times 512$-pixel resolution with $2 \mathrm{~ms}$ per pixel of dwell time. Secondary ion species $\left({ }^{12} \mathrm{CH}^{-},{ }^{16} \mathrm{O}^{-},{ }^{12} \mathrm{C}^{14} \mathrm{~N}^{-},{ }^{13} \mathrm{C}^{14} \mathrm{~N}^{-},{ }^{31} \mathrm{P}^{-},{ }^{32} \mathrm{~S}^{-}\right.$, and $\left.{ }^{31} \mathrm{P}^{16} \mathrm{O}_{2}{ }^{-}\right)$ were collected in parallel. A mass resolving power $(\mathrm{M} / \Delta \mathrm{M})$ between 8000 and 12,000 was achieved as previously described, with $40 \mu \mathrm{m}$ exit slits. Look@NanoSIMS software (LANS) was used to process the acquired secondary ion images [36]. More than 25 scans of each field of view were accumulated after lateral drift corrections. Region of interest (RoI) was manually defined for each individual cell along its inner margin based on ${ }^{12} \mathrm{C}^{14} \mathrm{~N}^{-}$ion images. The raw ion counts of ${ }^{13} \mathrm{C}^{14} \mathrm{~N}^{-}$and ${ }^{12} \mathrm{C}^{14} \mathrm{~N}^{-}$were used to calculate the fraction of $\mathrm{C}$ assimilated by a single cell $\left(\mathrm{K}_{\mathrm{A}}\right)$. Assimilation rates of carbon $\left(\mathrm{F}_{\mathrm{c}}\right)$ were derived for individual cells as described previously [37]. The total number of analyzed cells and those showing ${ }^{13} \mathrm{C}$-enrichment in each soil sample are summarized in Supplementary Table 3.

\section{Metagenomic sequencing and data analysis}

DNA extracted from unlabeled soil microcosms after $96 \mathrm{~h}$ incubation was sequenced on a MiSeq (Illumina) V3 platform $(2 \times 300$ cycles), resulting in $>2$ million paired-end reads for each soil sample $(n=4)$. The raw reads were quality filtered using Trimmomatic v.0.33 [38] (SLIDINGWINDOW:4:15; MINLEN 36) and assembled into contigs using Spades v3.14.0 [39] with the following the parameters (-meta; -k 21,33,55,77,99,127). Short contigs $\leq 500 \mathrm{bp}$ were removed. Metagenomic binning was performed using MetaBAT v0.32.4 [40] with -minContig option of 1500. The generated MAGs were further refined using RefineM v0.0.25 [7] based on genomic properties (i.e., tetranucleotide frequency and read coverage) and taxonomic classification. MAGs of interest were further refined by reads mapping, reassembly, and binning. Reads were mapped to the selected MAGs at a minimum alignment identity of $90 \%$ using BBMap v.38.51 (minid option). Reassembly and binning followed the same pipeline described above. The quality (completeness and contamination) of each MAG was assessed using CheckM v1.1.2 [41] with the lineagespecific workflow. Taxonomy assignments of MAGs were conducted using GTDB-Tk [42]. The genome tree of bacterial MAGs was inferred from the concatenation of 120 proteins using RAxML v8.2.11 [43] with 100 bootstrap replicates (-m PROTCAMMALG -f a -N 100). For MAGs, protein-coding genes were called using Prodigal [44] (-p single option) and the translated protein sequences were annotated with KEGG [45], Pfam [46], and EggNOG [47] databases. To search for aerobic biphenyl-oxidation pathways in genomes, reference protein sequences from the $b p h$ operon of various known biphenyl degraders, including Gram-positive and Gram-negative bacteria (Supplementary
Table 4), were queried against MAGs using Blastp [48] (E-value, 1e-20; minimum sequence identity, 30\%). The resulting blast hits were manually curated based on sequence length, domain composition, and conserved functional sites. To reconstruct the phylogenetic tree of $\mathrm{BphA}$, protein sequences were aligned using Muscle v3.8.1551 [49], followed by trimming of ambiguous sites in the alignment using trimAl v1.4 [50] with -automatedl option. Maximum likelihood trees were calculated using RAxML with the PROTGAMMALG evolutionary model.

\section{Metaproteomics and protein stable isotope probing}

In the protein-SIP experiment, soils incubated with unlabeled and labeled biphenyl $\left(20\right.$ atom $\left.\%{ }^{13} \mathrm{C}\right)$ were processed in parallel. Extraction and quantification of proteins from soil microcosms $(3 \mathrm{ml})$ were carried out using NoviPure Soil Protein Kit (QIAGEN) and BCA Protein Assay Kit (QIAGEN), respectively. The extracted proteins were separated by sodium dodecyl sulfate-polyacrylamide gel electrophoresis (SDS-PAGE). For each sample, the corresponding SDS-PAGE gel lane was cut into two pieces. Protein in the gel pieces was reduced with dithionite, carbamidomethylated with iodoacetamide, and digested with trypsin as described by Budhraja et al (2021). Peptides were purified using ZipTip C18-columns (Millipore) and analyzed by an Orbitrap Fusion Tribrid mass spectrometer (Thermo Scientific) equipped with a nanoLC system (Dionex Ultimate 3000RSLC; Thermo Scientific) [8, 51].

The obtained MS/MS spectra were searched against the specific metagenome database (bulk assembly) by XTandem [52] in the OpenMS pipeline [53]. Precursor and fragment ion mass tolerance were set to $5 \mathrm{ppm}$ and $0.02 \mathrm{Da}$, respectively. Two tryptic miss cleavages were allowed; carbamidomethylation of cysteines was treated as fixed modification and oxidation of methionine as a dynamic modification. Proteins were considered to be identified when at least two unique peptides were recovered with medium confidence (False discovery rate, FDR <0.05).

Incorporation of ${ }^{13} \mathrm{C}$ was determined for peptides at a high confidence level (FDR < 0.01) using MetaProSIP [54] with a mass window of $10 \mathrm{ppm}$. Centroid MS1 data, the metagenome database, and feature data annotated with identification (generated by IDMapper in OpenMS) were fed as input for MetaProSIP. A minimum correlation of 0.8 was set as the threshold for reporting ${ }^{13} \mathrm{C}$-peptides to reduce false positives. Relative isotope abundance (RIA) and labeling ratio (LR) of peptides were retrieved for labeled peptides from the output of MetaProSIP. The isotope pattern of the labeled peptides was further evaluated by comparing the observed mass spectra with its theoretical distributions using Pearson's chi-squared test $\left(\chi^{2}\right)$ in $\mathrm{R}$ software. 
a

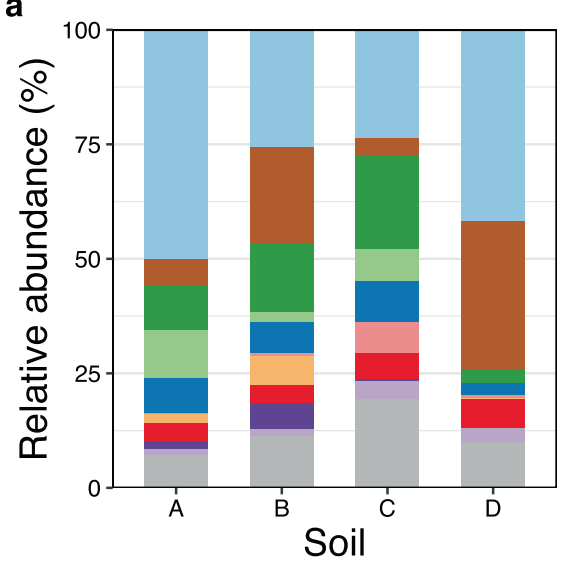

Phylum

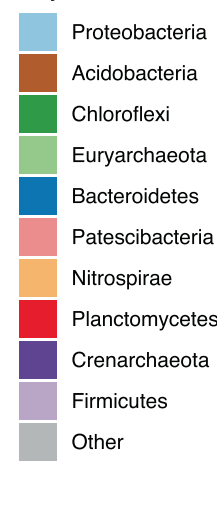

C

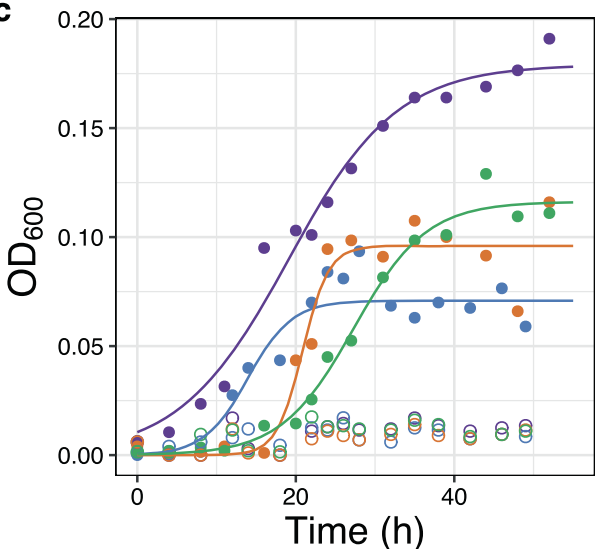

Substrate

- - Biphenyl

- + Bipheny

Enrichment

$\rightarrow$ A

$\rightarrow B$

$\rightarrow C$

$\rightarrow D$

Fig. 1 Biphenyl biodegradation potential in the four contaminated soils. a-b Relative abundance of major microbial lineages in each soil (a) and in the corresponding biphenyl-degrading enrichment cultures (b). c Growth curves of the biphenyl-degrading enrichment cultures when amended with biphenyl (filled circles), vs. control incubations (without biphenyl, open circles). Cultures A and C formed large flocs

\section{Results}

\section{Soil microbial diversity and biphenyl biodegradation potential}

Soil samples were collected at four different sites with a long history of contamination with aromatic compounds. Polychlorinated biphenyls (PCBs) were among the most prominent contaminants (Supplementary Table 1). Since microorganisms often use similar biochemical pathways to oxidize both biphenyl and PCBs [16], we hypothesized that the sampled soils contained biphenyl-oxidizing microorganisms. Amplicon sequencing of $16 \mathrm{~S}$ rRNA genes indicated that all four soils harbored highly diverse microbial communities. A total of $18,188,29,517,49,167$, and 35,121 operational taxonomic units (OTUs) were observed for soils A, B, C, and D, respectively. Among these, OTUs affiliated with Proteobacteria accounted for more than $20 \%$ of all sequences in each soil type. The remaining bacterial

\section{b}

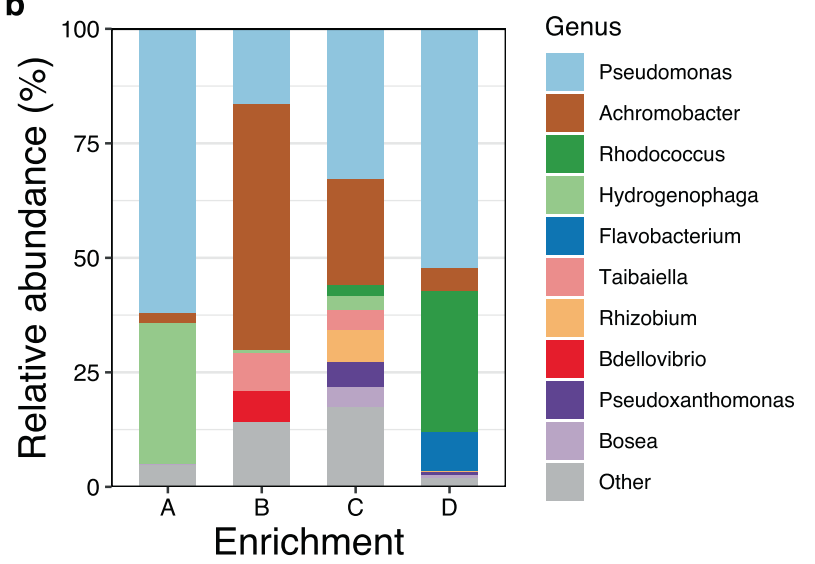

d

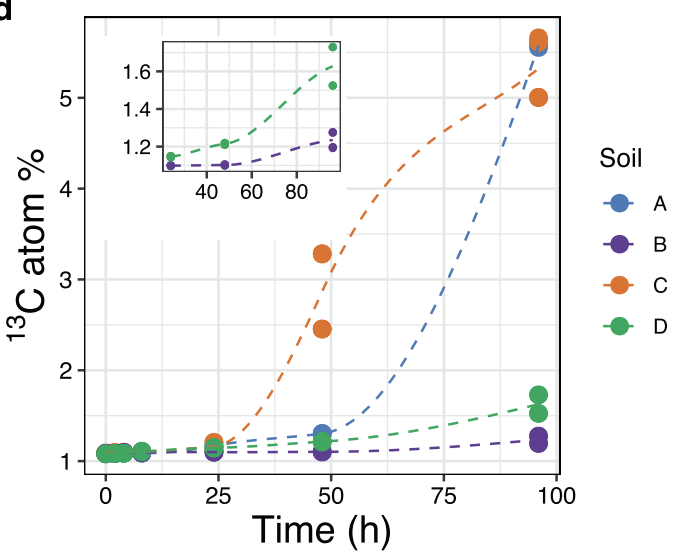

after $24 \mathrm{~h}$ of incubation, which led to high OD scattering. d Evolution of ${ }^{13} \mathrm{CO}_{2}$ in the headspace of soil microcosms incubated with ${ }^{13} \mathrm{C}$ biphenyl. The last three times points of soil B and D were replotted as an inset to show the mineralization of ${ }^{13} \mathrm{C}$-biphenyl. Duplicate assays were done for each soil type. For soil A, only one of the replicates was active.

sequences were assigned to Acidobacteria (4-33\%), Chloroflexi (3-20\%), Bacteroidetes (3-9\%), and Planctomycetes (4-6\%) (Fig. 1a). Archaea (mostly Euryarchaeota and Crenarchaeota) contributed to $8-12 \%$ of total sequences in soils $\mathrm{A}, \mathrm{B}, \mathrm{C}$, and less than $0.5 \%$ in soil $\mathrm{D}$. Overall, the dominant phyla detected here matched the microbial diversity typically associated with PCBcontaminated soils [55].

Cultivation experiments showed that all soils had the potential to oxidize biphenyl, with biphenyl-dependent microbial growth observed within 5 to 10 days of incubation. Sediment-free biphenyl-oxidizing enrichment cultures were obtained from each soil type. These cultures formed typical yellow meta-cleavage intermediates during growth (not shown) [56]. The approximate doubling time calculated from the OD-based growth curves ranged from $1.6 \mathrm{~h}$ to $5.7 \mathrm{~h}$. Taxonomic profiling based on 16S rRNA genes revealed that the enrichments were dominated by Pseudomonas, Achromobacter, Rhodococcus, Hydrogenophaga, 

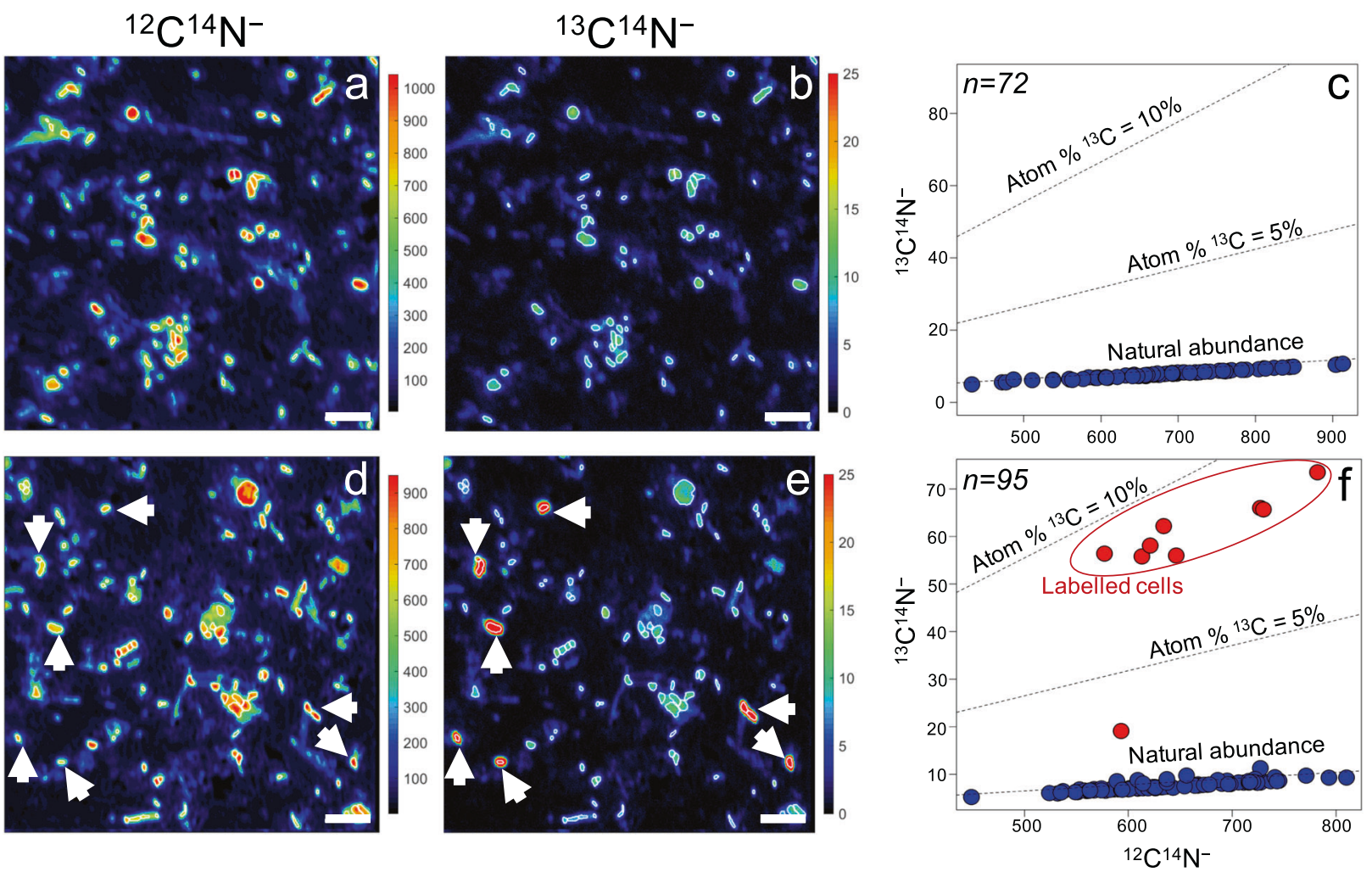

Fig. 2 NanoSIMS analysis of cells extracted from soil $\mathrm{C}$ after incubation with ${ }^{13} \mathrm{C}$-labeled biphenyl for $0(a-c)$ and $96 \mathrm{~h}(\mathrm{~d}-\mathrm{f})$. Secondary ion images of ${ }^{12} \mathrm{C}^{14} \mathrm{~N}^{-}(\mathbf{a}, \mathbf{d})$ and ${ }^{13} \mathrm{C}^{14} \mathrm{~N}^{-}(\mathbf{b}, \mathbf{e})$ were used to identify individual cells and to quantify ${ }^{13} \mathrm{C}$ abundance. Arrowhead in ${ }^{12} \mathrm{C}^{14} \mathrm{~N}^{-}$ion image (d) point to the cells enriched in ${ }^{13} \mathrm{C}$ in panel $\mathbf{e}$.

and Flavobacterium (Fig. 1b). Members of these genera have been frequently shown to degrade biphenyl [12], suggesting a similar function in the obtained cultures.

Short-term labeling experiments with ${ }^{13} \mathrm{C}$-biphenyl demonstrated that biphenyl-oxidizing microorganisms were present and active in all original soils. The formation of ${ }^{13} \mathrm{CO}_{2}$ was detected in microcosms of all soil types, albeit at different extent, indicating different biphenyl mineralization rates. The fastest response was measured for soil $\mathrm{C}$, where ${ }^{13} \mathrm{CO}_{2}$ was detected within $24 \mathrm{~h}$ and continued to increase in concentration throughout the experiment, reaching 5.2 atom\% labelings within 4 days of incubation (Fig. 1d). In contrast, longer lag phases and lower abundances of ${ }^{13} \mathrm{CO}_{2}$ were observed for soils A, $\mathrm{B}$, and $\mathrm{D}$.

\section{Visualization of soil biphenyl-degraders at a single- cell level}

Mineralization of ${ }^{13} \mathrm{C}$-biphenyl was expected to be accompanied by assimilation of ${ }^{13} \mathrm{C}$ by biphenyl oxidizers. To test this hypothesis, subsamples of the labeling assays collected at $0,24,48$, and $96 \mathrm{~h}$ of incubation were analyzed by
Raw ion counts of ${ }^{12} \mathrm{C}^{14} \mathrm{~N}^{-}$and ${ }^{13} \mathrm{C}^{14} \mathrm{~N}^{-}$for individual cells were shown as scatter plots $(\mathbf{c}, \mathbf{f})$. Cells having ${ }^{13} \mathrm{C}$ abundance over $2 \%$ are presented as red symbols (f), whereas other cells are presented as blue symbols $(\mathbf{c}, \mathbf{f})$. Scale bars $=3.5 \mu \mathrm{m}$.

nanoSIMS. Individual cells were defined based on secondary ion images of ${ }^{12} \mathrm{C}^{14} \mathrm{~N}^{-}$and ${ }^{13} \mathrm{C}^{14} \mathrm{~N}^{-}$. The ${ }^{13} \mathrm{C}$ abundance was determined for each cell. After $96 \mathrm{~h}$ of incubation, cells showing substantial enrichment in ${ }^{13} \mathrm{C}$ were observed in all four soils (Fig. 2 and Supplementary Figs. 3-7). Most showed ${ }^{13} \mathrm{C}$ enrichment close to the substrate labeling ratio (10 atom\%) at the single-cell level. The relatively short incubation time and the high labeling ratio indicated that labeled cells were most likely primary biphenyl oxidizers, although the presence of secondary consumers feeding on excreted metabolites cannot be presently excluded. Biphenyl oxidizers are known to metabolize biphenyl to benzoate or other intermediates, which can be excreted and serve as a growth substrate for other members of the microbial communities [57, 58]. The variations in ${ }^{13} \mathrm{C}$ abundance among individual cells could be caused by metabolic heterogeneity of primary biphenyl oxidizers $[59,60]$, or by poor substrate availability in the soil matrix. Alternatively, the less ${ }^{13} \mathrm{C}$-enriched cells may represent secondary consumers. Quantitatively, the cells enriched in ${ }^{13} \mathrm{C}$ accounted for approximately $11 \%, 3 \%$, $15 \%$, and $8 \%$ of the total cell number of soils $\mathrm{A}, \mathrm{B}, \mathrm{C}$, and $\mathrm{D}$, respectively. 
Carbon assimilation rate $\left(F_{c}\right)$ was calculated using the cellular ${ }^{13} \mathrm{C}^{14} \mathrm{~N}^{-} /{ }^{12} \mathrm{C}^{14} \mathrm{~N}^{-}$ratios and cell volumes calculated for regions of interest of nanoSIMS images [37]. For the calculation, we considered for all individual cells an average carbon density of $93.4 \mathrm{fg} \times \mu^{-3}$ (average of several Proteobacteria isolates [61, 62]), since Proteobacteria was the most abundant microbial group in all tested soils. The cells showing enrichment in ${ }^{13} \mathrm{C}$ have assimilation rates up to $0.61 \mathrm{fg} \mathrm{cell}^{-1} \mathrm{~h}^{-1}$ for soil $\mathrm{A}, 0.40 \mathrm{fg} \mathrm{cell}^{-1} \mathrm{~h}^{-1}$ for soil $\mathrm{B}$, $2.9 \mathrm{fg} \mathrm{cell}^{-1} \mathrm{~h}^{-1}$ for soil C, and $0.96 \mathrm{fg} \mathrm{cell}^{-1} \mathrm{~h}^{-1}$ for soil D. To our knowledge, this is the first study reporting carbon assimilation rates for single cells of hydrocarbon-degrading microorganisms directly in soil environments.

\section{Phylogenetic identification of biphenyl degraders using protein-SIP}

Since microbial communities of all soils were highly diverse, a FISH-based phylogenetic identification of the ${ }^{13} \mathrm{C}$-labeled cells via a correlative FISH-SIMS analysis was not possible. Instead, we opted for a high-throughput protein-SIP-metagenomics approach. For this, we used microcosm subsamples collected at $96 \mathrm{~h}$ incubation with labeled biphenyl since these showed the highest rates of substrate assimilation (Fig. 2 and Supplementary Fig. 7).

Metagenome sequencing of each sample was conducted to an average depth of 2.8 million reads. For soils A, B, C, and D de novo assembly yielded 274,602, 219,108, 554,918, and 236,566 scaffolds, respectively. Predicted open reading frames were compiled as soil-specific databases for global metaproteomic analyses. Soil proteins extracted from microcosms with labeled and unlabeled biphenyl were analyzed in parallel. Querying mass spectra against the protein databases resulted in the identification of 345, 410, 1070, and 1986 peptides, from 381, 349, 1599, and 1506 proteins for soil A, B, C, and D, respectively. The most frequently detected proteins were affiliated to Proteobacteria, Chloroflexi, Acidobacteria, and Bacteroidetes (Fig. 3a), consistent with taxa abundance revealed by $16 \mathrm{~S}$ rRNA amplicon sequencing (Fig. 1a).

For the identified proteins, we analyzed the ${ }^{13} \mathrm{C}$ incorporation level by comparing mass spectra of identified peptides from ${ }^{13} \mathrm{C}$-labeled vs. unlabeled microcosms. As an example, in soil A the peptide VVNAEAGNAR which is part of the PAH dioxygenase large subunit, showed a shift of the most abundant isotopomer from $\mathrm{m} / \mathrm{z}$ of $500.7622(z=2)$ to $504.7756(z=2)$, accompanied by a Gaussian-like shaped isotopic pattern (Fig. 3b). The extent of the mass shift represented a relative isotope abundance (RIA) of $18.4 \%$, close to the ${ }^{13} \mathrm{C}$ abundance of the labeled substrate (20 atom\% for protein-SIP). These results demonstrated ${ }^{13} \mathrm{C}$ assimilation into proteins and suggested that the incorporation was achieved via direct substrate utilization, and not indirectly through a food web in which the label would be diluted. A similar ${ }^{13} \mathrm{C}$ incorporation pattern was observed for 5 and 11 peptides in soils A and D (Supplementary Figs. 8-10), whereas no ${ }^{13} \mathrm{C}$-labeled peptides were detected in soils $\mathrm{B}$ and C. Possible reasons include the stringency of the statistical approach, low abundance of biphenyl degraders (i.e., in soil B), high complexity of the microbial community (i.e., soil C) or moderate recovery of soil proteins (soils B and C).

Phylogenetic classification of potential biphenyl degraders was achieved by mapping the ${ }^{13} \mathrm{C}$-labeled peptides to metagenome-assembled genomes (MAGs). Binning of the four assembled metagenomes resulted in a total of 15 medium to high-quality MAGs ( $>50 \%$ completeness and $<10 \%$ contamination) comprising taxonomically distinct members of Patescibacteria, Doudnabacteria, Gemmatimonadetes, and Proteobacteria (Fig. 3c and Supplementary Tables 5-6). An average of 40 proteins was identified across all 15 MAGs, demonstrating their viability and activity in soils (Fig. 3c). Of these, the MAGs classified as Alphaproteobacteria (D_bin4) and Azoarcus (D_bin1) encoded 4 and, respectively, 6 uniquely mapped ${ }^{13} \mathrm{C}$-labeled peptides, indicating active biphenyl assimilation (Fig. 3c). A third MAG classified as uncultured Rugosibacter (A_bin2) encoded three unique ${ }^{13}$ C-labeled peptides. However, since for this MAG only a total of 5 unique proteins were identified (Fig. 3c), its assignment as active biphenyl oxidizer is tentative.

\section{Biphenyl degradation pathway in SIP-identified biphenyl-degraders}

Each of the three MAGs identified by protein-SIP provided further genomic evidence for the utilization of biphenyl (Fig. 4). All three MAGs contained genes encoding homologs of biphenyl dioxygenase (BPDO), the first enzyme of the biphenyl oxidation pathway [16]. To confirm the relatedness of these genes to known BPDO, we constructed a phylogenetic tree using proteins of the BPDO catalytic subunit (BphA). This analysis revealed that the BphAs from D_bin1 and D_bin4 belonged to a toluene/biphenyl dioxygenase (T/B DO) clade closely related to those of biphenyl-degrading Burkholderia xenovorans LB400 and Pseudomonas furukawaii KF707 (Fig. 5a) [63, 64]. In contrast, BphAs encoded by A_bin2 exhibited higher sequence similarity with biochemically characterized BphA from Sphingobium yanoikuyae within the PAH-GN clade (Fig. 5a) [65]. In addition to $b p h A$ genes, D_bin4 and A_bin2 contained multiple copies of paralogs that were genetically distant and phylogenetically distinct from known BPDOs (Fig. 5a). These genes could possibly be responsible for the activation of aromatic compounds other than biphenyl (e.g., naphthalene).

Furthermore, all three MAGs contained genes of the biphenyl upper and lower pathways [16]. Specifically, these 


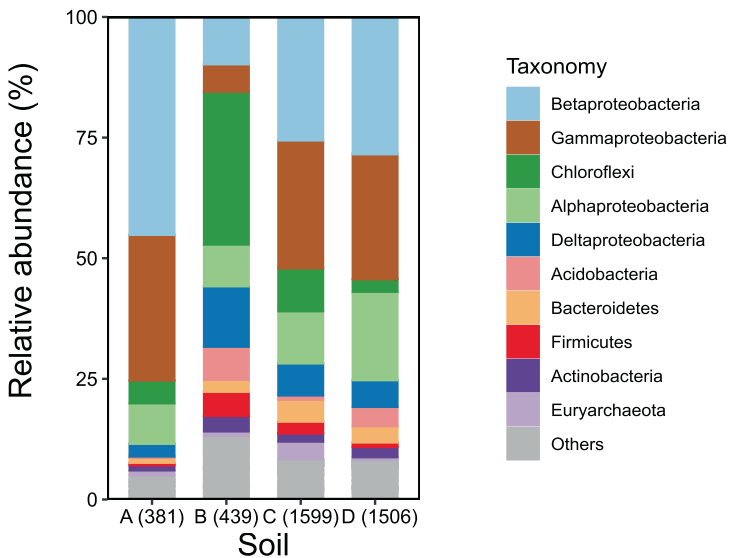

Lineage

Alphaproteobacteria Gemmatimonadetes Anaerolineales Paceibacteria Doudnabacteria Methylotenera Methylotenera Rugosibacter Azoarcus Pseudomonadales Moraxellaceae Moraxellaceae Porticoccaceae Alcanivoracaceae Alcanivoracaceae

a

Completeness (\%)

Phylogeny Bin Sample Contamination (\%)

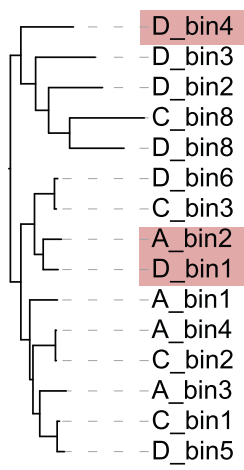

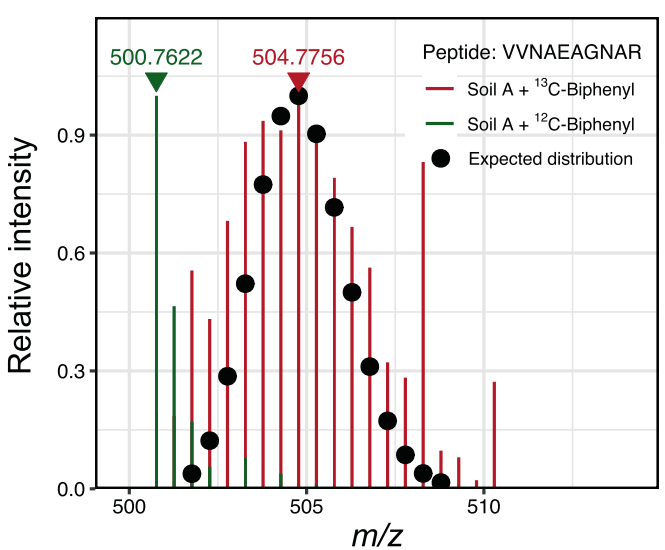

Identified proteins
Fig. 3 Identification of biphenyl-degrading microorganisms in soils using SIP-coupled metaproteomics. a Phylogenetic classification of identified proteins in four soil microcosms after 96-h incubation with biphenyl. The number in parenthesis indicates the number of identified proteins in the different soil samples. b Mass spectra of doubly charged peptide VVNAEAGNAR (PAH dioxygenase alpha subunit) in ${ }^{13} \mathrm{C}$ (red lines) and ${ }^{12} \mathrm{C}$ (green lines) microcosms. Black circles represent the best fit of the theoretical isotopic patterns. c Overview of

included genes encoding cis-2,3-dihydrobiphenyl-2,3-diol dehydrogenase (BphB), 2,3-dihydroxybiphenyl 1,2-dioxygenase (BphC), and 2-hydroxy-6-oxo-6-phenylhexa-2,4dienoate hydrolase $(\mathrm{BphD})$ for the upper pathway, and genes coding for 4-hydroxy-2-oxovalerate aldolase (BphI), 2oxopent-4-enoate hydratase $(\mathrm{BphH})$, and acetaldehyde dehydrogenase (BphJ) for the lower pathway (Figs. 4 and 6; Supplementary Table 7). In D_bin1 and D_bin4, genes for the upper and lower pathways were present in operons showing similar synteny with that of B. xenovorans LB400 [66]. In the Rugosibacter A_bin2, synteny was absent, the same set of genes being located at different genomic regions (Fig. 6).

The biphenyl upper and lower pathways yield eventually benzoate, which can be further metabolized to TCA intermediates via two different pathways. D_bin4 and A_bin2 encoded benzoate 1,2-dixoygenase (BenAB) and/ or catechol 2,3-dioxygenase (DmpB) (Supplementary Table 8), suggesting the corresponding microorganisms were able to oxidize benzoate via the catechol meta- medium-quality to high-quality MAGs obtained in this study. Phylogenetic classification, tree, and soil of origin for each MAG are shown on the left. Phylogeny of MAGs was reconstructed based on a concatenated alignment of 120 bacterial marker genes. Bars indicated the completeness, contamination, number of identified proteins, and number of detected ${ }^{13} \mathrm{C}$-peptides for each MAG. MAGs encoding ${ }^{13} \mathrm{C}$ peptides are shaded by pink boxes.

cleavage pathway [67]. By contrast, D_bin1 appeared to oxidize benzoate via the benzoyl-CoA pathway, as shown by the presence of genes coding benzoate coenzyme $\mathrm{A}$ ligase (BadA) and benzoyl-CoA 2,3-epoxidase (BoxAB) [68]. Finally, all three MAGs encode complete TCA cycle enzymes and multiple aerobic respiration complexes that could enable them to completely oxidize biphenyl to $\mathrm{CO}_{2}$ and conserve energy via oxygen respiration, consistent with a strict or facultative aerobic lifestyle (Supplementary Tables 9-10). These findings further consolidated the identification of the uncultured Alphaproteobacteria (D_bin4) and Azoarcus (D_bin1) as active biphenyldegrading microorganisms in the tested soils. Although the uncultured Rugosibacter A_bin2 encodes two BphAs highly similar to biochemically characterized enzymes and all genes required for complete biphenyl oxidation, it lacks the syntenic organization of the $b p h$ genes typical of biphenyl oxidizers. Its assignment as biphenyl oxidizer remains therefore cautious. 


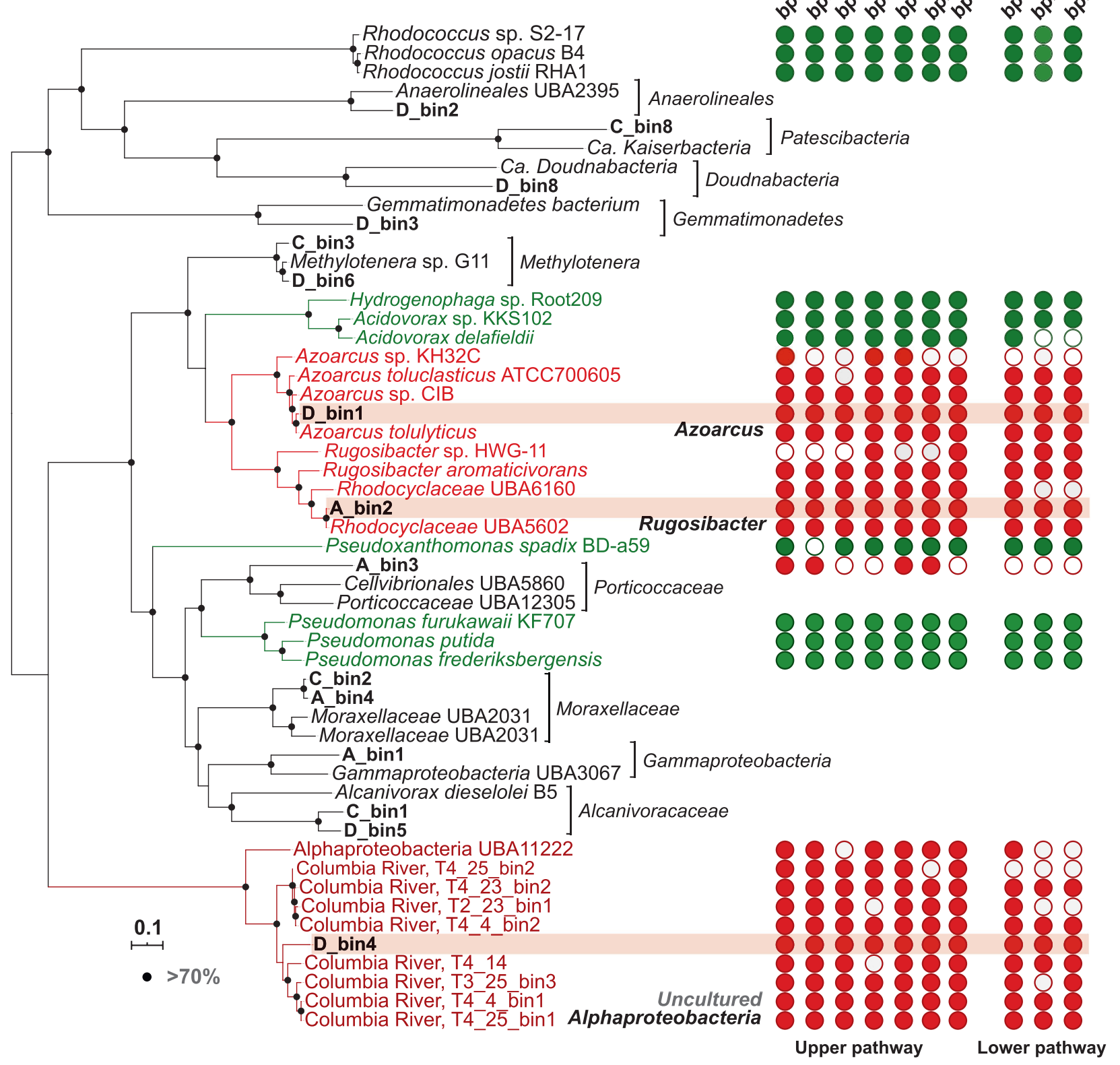

Fig. 4 Phylogenetic placement of 15 MAGs recovered from soils. Tree clades containing ${ }^{13} \mathrm{C}$-labeled MAGs detected in this study are shown in red. Known biphenyl-degrading species are highlighted in green. The genomic tree was built from the concatenation of 120 bacterial marker genes. Filled circles on tree nodes indicated bootstrap values $>70 \%$. Scale bar, amino acid substitutions per site. The distribution of $b p h$ genes is shown in the right panel. Filled and empty circles represent the presence or absence of $b p h$ genes. The gene distribution is not shown for lineages without detectable bph

\section{Discussion}

Here we explored the largely uncultured soil microbiota mediating organic pollutants degradation via an experimental framework that integrated stable isotope probing with single-cell analysis and isotope-specific molecular homologs. Abbreviations: $b p h A$ : biphenyl dioxygenase subunit alpha; $b p h E$ : biphenyl dioxygenase subunit beta; $b p h F$ : biphenyl dioxygenase ferredoxin component; $b p h G$ : biphenyl dioxygenase system ferredoxin/NAD ${ }^{+}$reductase component; $b p h B$ : cis-2,3-dihydrobiphenyl2,3-diol dehydrogenase; $b p h C$ : 2,3-dihydroxybiphenyl 1,2-dioxygenase; $b p h D$ : 2-hydroxy-6-oxo-6-phenylhexa-2,4-dienoate hydrolase; bphI: 4-hydroxy-2-oxovalerate aldolase; bphH: 2-oxopent-4-enoate hydratase; $b p h J$ : acetaldehyde dehydrogenase.

biology approaches. Biphenyl-assimilating microorganisms were visualized directly in soils via nanoSIMS chemical imaging. With this approach, we determined both the abundance of active biphenyl oxidizers in different soils and their rates of biphenyl assimilation (Fig. 2). Taxonomic identification of labeled cells based on protein-SIP showed 


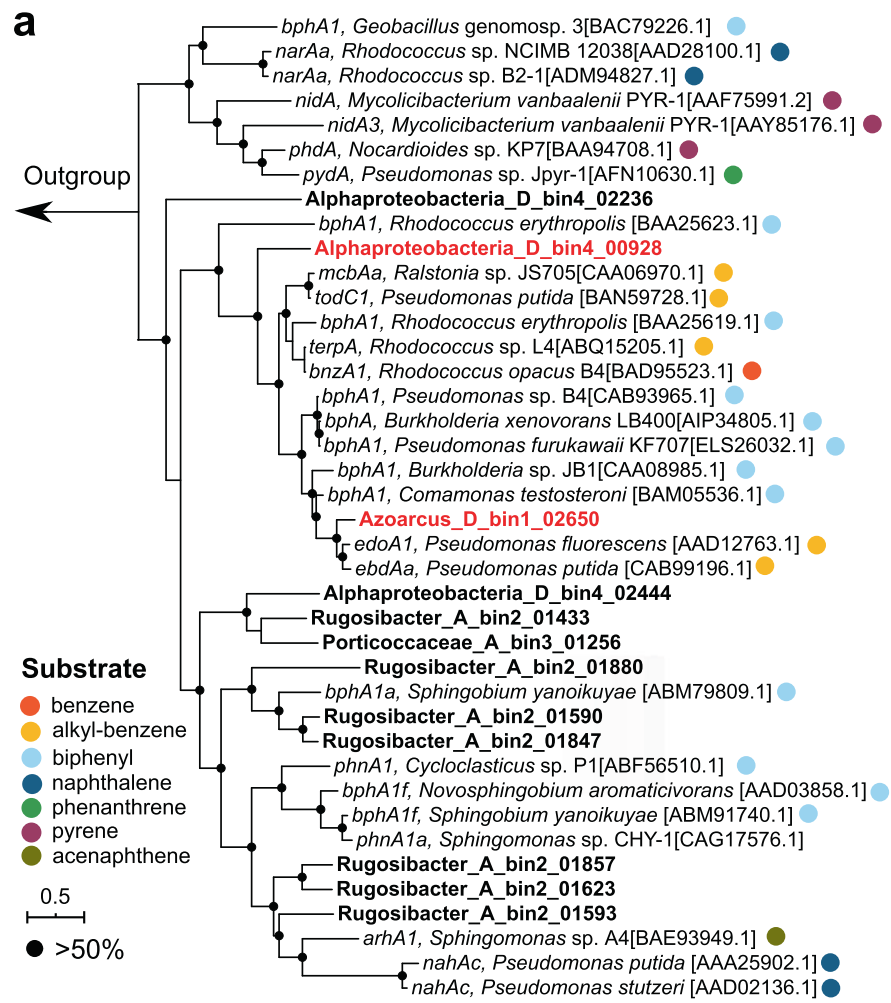

b

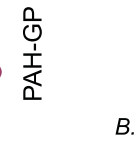

B. xenovorans LB400 M H TT H Y S VGQ TFNI NF D

P. furukawaii KF707 M H MS H F M VGQ AITT T F D

Burkholderia sp. JB1 MH MS H F I VGQ GITT T F D

Azo_D_bin1_02650 M H MS H F I VGQ GITT T Y D

Pseudomonas sp. B4 MH MA H Y T VGQ AITT T F D

C. testosteroni MH MAHF IVGQ GITS T F D

Alpha_D_bin4_00928 MH VS H F L L G A GVTA T L D

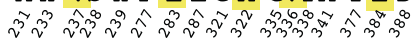

C

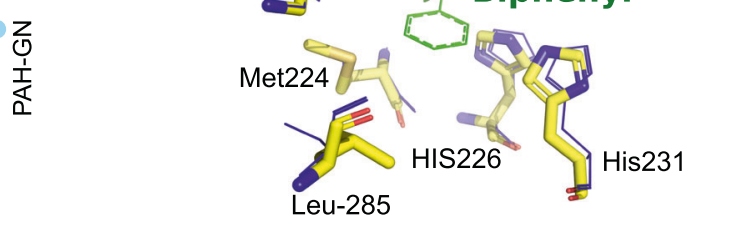

Fig. 5 Phylogeny and homology modeling of the alpha subunit of biphenyl dioxygenase (BphA). a BphA homologs from metagenomic bins are shown in bold font, and those affiliated to toluene/biphenyl dioxygenase (DO) are highlighted in red color. Filled circles on the tree branches indicated the bootstrap values $>50 \%$. The scale bar represents the number of substitutions per site. PAH-GN (GP): PAH dioxygenase from Gram-negative (Gram-positive) bacteria; T/B DO: toluene/biphenyl dioxygenase. b Sequence alignment of BphA from A_bin2, D_bin4, and well-known biphenyl degraders. Sequence

an obvious difference between biphenyl oxidizers active under near in situ conditions and species enriched via repeated sub-cultivation. In contrast to well-known biphenyl degraders yielded by the cultivation-dependent approach, our labeling approach revealed previously unrecognized functions of uncultured yet ecologically relevant species. The clade UBA11222 represents such an uncultivated Alphaproteobacteria lineage whose physiological functions remained so far undocumented, despite their broad distribution in terrestrial and marine environments associated with organic contaminants (Supplementary Fig. 11) [7, 69]. Here we provided both physiological and genomic evidence that members of this clade are able to derive carbon and energy from the oxidation of biphenyl (Figs. 2 and 3). Considering that aromatic hydrocarbon oxidation pathways often have extended substrate spectra and that biphenyl-oxidizing microorganisms can often cometabolize PCBs, members of this clade may have broader environmental implications in biodegradation processes. In addition, the combination of activity probing and genomic reconstruction indicated greater biodegradation capacities regions that influenced the PCB congener preference and regiospecificity of biphenyl dioxygenase, are displayed $[79,80]$. B. xenovorans: Burkholderia xenovorans; P. furukawaii: Pseudomonas furukawaii; C. testosteroni: Comamonas testosteroni. The amino acid numbering corresponds to BphA of the B. xenovorans LB400 sequence. c, Modeled substrate binding pocket in the BphA of D_bin4. The predicted BphA structure (yellow sticks) was superimposed on B. xenovorans BphA (blue wireline). The biphenyl molecule is shown as green lines.

for known hydrocarbon-degrading bacteria. Strains of Azoarcus and Rugosibacter have been frequently retrieved as toluene and pyrene degraders, respectively [70, 71]. Their in situ activities towards biphenyl, as revealed (Azoarcus) or suggested (Rugosibacter) here, thus indicate a broader substrate range and higher metabolic versatility than previously recognized.

Genome analysis of taxa that we identified as active hydrocarbon oxidizers provided novel mechanistic insights regarding biodegradation processes in nature. Biphenyl dioxygenase (BPDO), the key enzyme for biodegradation of biphenyl and its analogs (i.e., PCBs), was detected in all three SIP-identified bacteria. The BPDO from the clade UBA11222 apparently belonged to an offset cluster within biphenyl/toluene dioxygenase family [72], with clear separation from those of cultivated biphenyl-utilizing bacteria (Fig. 5a). Their catalytic subunit (BphA) exhibited distinct sequence patterns of amino acids that were known to influence enzyme-substrate specificity and regiospecificity (Fig. 5b). Consistently, structure modeling of BphA from UBA11222 based on the available BphA crystal 


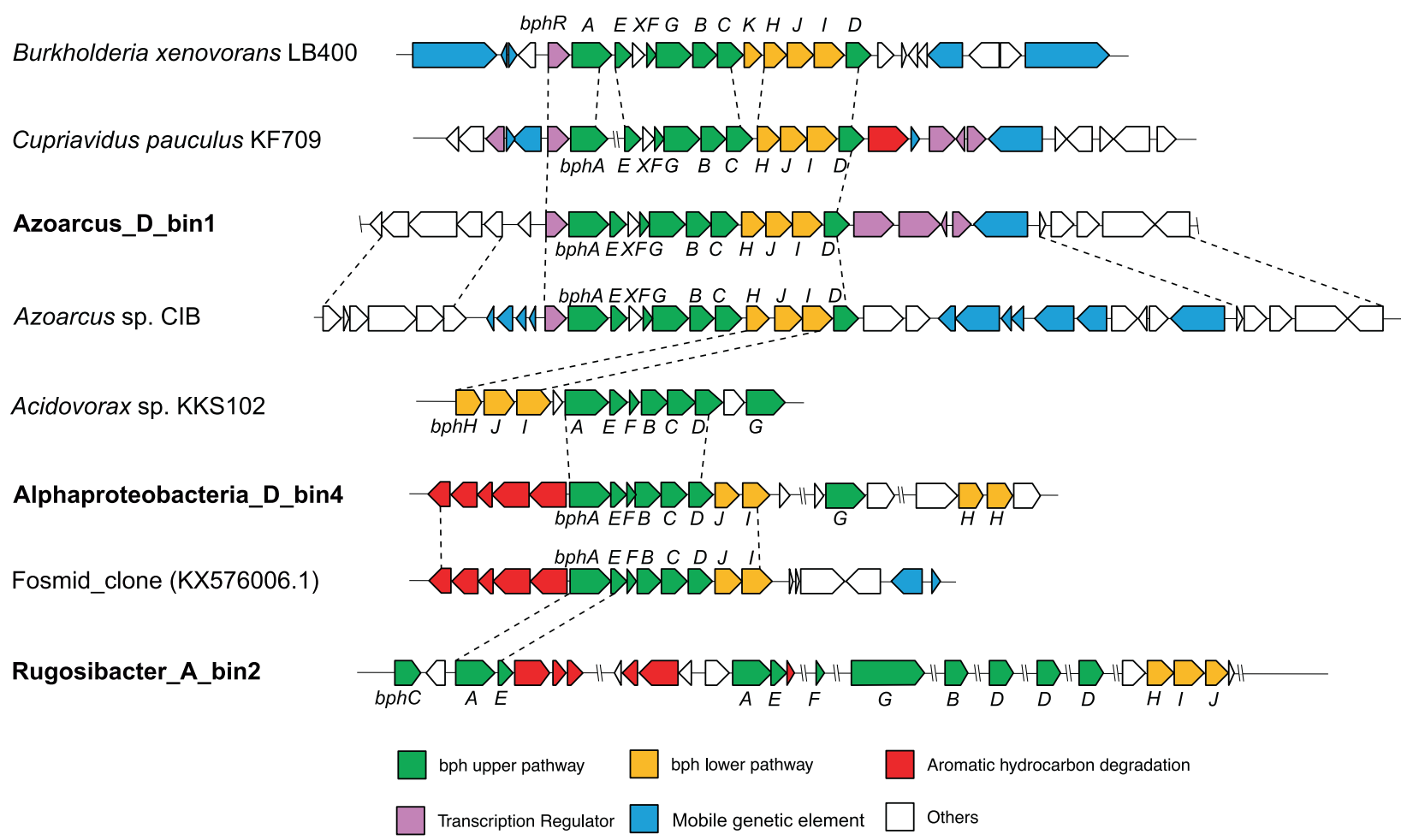

Fig. 6 Alignment of genomic region(s) of three ${ }^{13} \mathrm{C}$-labeled MAGs encoding $b p h$ genes with corresponding regions of reference genomes. Conserved genomic regions with similar gene organization are highlighted using dashed lines. structure (Burkholderia xenovorans LB400) revealed differences between the amino acid sequences of the substratebinding pocket (Fig. 5c). Replacement of an aromatic amino acid by an aliphatic residue may allow UBA11222 BPDO to accommodate different sets of PCB substrates. These results extend the genetic diversity of $b p h A$ in soil environments and imply a divergent function of BPDO in uncultured biphenyl-degrading microorganisms compared to cultivated counterparts. In two SIP-identified MAGs from soil $\mathrm{D}, b p h A$ was found at genomic regions enriched in mobile genetic elements (MGEs), including those encoding transposes and integrase (Fig. 6). This concurs with previous findings of close genetic associations between MGEs and catabolic genes in isolated PCB-degrading microorganisms [16]. These observations suggest that horizontal gene transfer (HGT) mediated by MGEs may play a major role in the in situ dissemination of catabolic pathways, potentially allowing rapid adaptation of microbial communities to organic pollutants [73]. In addition, metabolic capacities of complete biphenyl oxidation were apparently conserved across phylogenetically distinct MAGs retrieved from the same soil, suggesting some functional plasticity of the soil microbial communities. This appears distinct from oil-degrading microbial communities of oil-contaminated environments, where the main catabolic pathways are partitioned among individual community members, and complete oxidation of hydrocarbons is achieved by complex coordination between microorganisms carrying out nonredundant reactions [74]. This disparity reflects diverse modes of microbial biodegradation networks in the environment [75].

All the ${ }^{13} \mathrm{C}$-labeled peptides identified here were mapped to MAGs with a genetic makeup indicating a potential for complete oxidation of biphenyl. However, nanoSIMS analyses showed a small number of cells becoming lightly enriched in ${ }^{13} \mathrm{C}$ during the later incubation times (Fig. 2, Supplementary Figs. 3-7). These could represent secondary consumers feeding on metabolites excreted by the primary biphenyl oxidizers. The most likely reasons secondary consumers were not apparent in the protein-SIP analyses were their relatively low abundance and low ${ }^{13} \mathrm{C}$ enrichment level. Future studies employing time-resolved ecophysiology probing over longer incubation times are needed to resolve metabolic networks involved in the degradation of biphenyl or other contaminants and to reveal the identity of secondary consumers.

Our findings have two kinds of implications. On the one hand, taxonomic identification of resident clades and measurement of their near-in-situ hydrocarbon uptake rates may assist to devise tailored bioremediation strategies. We showed that it was uncultured taxa distinct from those retrieved by enrichment approaches that responded readily 
to biphenyl additions under near in situ conditions. For example, in slurries of soil D, we identified Azoarcus, while cultivation yielded Pseudomonas and Rhodococcus. Azoarcus and the related Aromatoleum and Thauera genera are best known for their metabolic plasticity and ability to oxidize aromatic hydrocarbons under nitrate-reducing conditions (Supplementary Fig. 12) [76]. Therefore, in environments like soil $\mathrm{D}$, a more effective bioremediation strategy might be to enhance the natural attenuation potential for example by stimulating nitrate reduction, instead of the more common practices of aeration or injection of oxygen [77, 78].

On the other hand, the wealth of metabolic pathways retrieved during the past decade via environmental sequencing is in dire need of direct evidence for their functionality $[10,11]$. Extending the approach used here to other substrates and environments may allow testing of predicted ecophysiologies, uncover in situ metabolic networks, or identify metabolically active microorganisms, which, as shown here, could be rather different than those obtained via long-time cultivation. Combined with rapid innovations in cultivation strategies [4], direct in situ or near in situ ecophysiology probing is one of the awaited approaches to expand our knowledge of the metabolic potential and ecological roles of members of the uncultured majority.

\section{Data availability}

Sequencing data are archived in the NCBI database under BioProject number PRJNA692092, including the metagenome and $16 \mathrm{~S}$ rRNA gene amplicon datasets for soil A (SAMN17313532), B (SAMN17313578), C (SAMN17313580), and D (SAMN17313590). Metagenomeassembled genomes (MAGs) of uncultured biphenyldegrading bacteria, including Rugosibacter_A_bin2 (SAMN17315487), Azoarcus_D_bin1 (SAMN17315485), and Alphaproteobacteria_D_bin4 (SAMN17315486), have been submitted to NCBI under the same BioProject. The proteomics dataset has been deposited with the ProteomeXchange Consortium identifier PXD023646. All other data are available in the paper or the Supplementary Information.

Acknowledgements We acknowledge B. Scheer for proteomics analyses and Dr. L. Polerecky (Utrecht University) for support with the LANS software. Funding for this project was provided by Helmholtz Association and by the National Natural Science Foundation of China (41991332). Further financial support was provided by the Helmholtz Association (grant ERC-RA-0020 to FM). We acknowledge the Centre for Chemical Microscopy (ProVIS) at the Helmholtz Centre for Environmental Research for the use of protein mass spectrometry and nanoSIMS. ProVIS is supported by European Regional Development Funds (EFRE-Europe funds Saxony).
Author contributions S-CC, G-LD, H-HR, Y-GZ, and FM designed the research. S-CC, G-LD, and FM retrieved the original soil sample and contributed to the establishment of the enrichment cultures. S-CC and FM performed labeling experiments. S-CC, FC, H.S., F.M., and N.M. designed and performed nanoSIMS analyses. S-CC, RB, H-HR, and LA. performed metaproteomics analyses. S-CC, G-LD, Y-GZ, and FM performed phylogenetic and metagenomics analyses. S-CC, YGZ, LA, and FM wrote the manuscript with contributions from all coauthors.

Funding Open Access funding enabled and organized by Projekt DEAL.

\section{Compliance with ethical standards}

Conflict of interest The authors declare no competing interests.

Publisher's note Springer Nature remains neutral with regard to jurisdictional claims in published maps and institutional affiliations.

Open Access This article is licensed under a Creative Commons Attribution 4.0 International License, which permits use, sharing, adaptation, distribution and reproduction in any medium or format, as long as you give appropriate credit to the original author(s) and the source, provide a link to the Creative Commons license, and indicate if changes were made. The images or other third party material in this article are included in the article's Creative Commons license, unless indicated otherwise in a credit line to the material. If material is not included in the article's Creative Commons license and your intended use is not permitted by statutory regulation or exceeds the permitted use, you will need to obtain permission directly from the copyright holder. To view a copy of this license, visit http://creativecommons. org/licenses/by/4.0/.

\section{References}

1. Singer E, Wagner M, Woyke T. Capturing the genetic makeup of the active microbiome in situ. ISME J. 2017;11:1949-63.

2. Hall EK, Bernhardt ES, Bier RL, Bradford MA, Boot CM, Cotner JB, et al. Understanding how microbiomes influence the systems they inhabit. Nat Microbiol. 2018;3:977-82.

3. Lloyd KG, Steen AD, Ladau J, Yin J, Crosby L. Phylogenetically novel uncultured microbial cells dominate earth microbiomes. mSystems 2018;3:e00055-18.

4. Lewis WH, Tahon G, Geesink P, Sousa DZ, Ettema TJG. Innovations to culturing the uncultured microbial majority. Nat Rev Microbiol. 2021;19:225-40.

5. Hug LA, Baker BJ, Anantharaman K, Brown CT, Probst AJ, Castelle CJ, et al. A new view of the tree of life. Nat Microbiol. 2016;1:16048.

6. Spang A, Caceres EF, Ettema TJG. Genomic exploration of the diversity, ecology, and evolution of the archaeal domain of life. Science. 2017;357:eaaf3883.

7. Parks DH, Rinke C, Chuvochina M, Chaumeil P-A, Woodcroft BJ, Evans PN, et al. Recovery of nearly 8,000 metagenomeassembled genomes substantially expands the tree of life. Nat Microbiol. 2017;2:1533-42.

8. Chen S-C, Musat N, Lechtenfeld OJ, Paschke H, Schmidt M, Said $\mathrm{N}$, et al. Anaerobic oxidation of ethane by archaea from a marine hydrocarbon seep. Nature 2019;568:108-11.

9. Nayfach S, Roux S, Seshadri R, Udwary D, Varghese N, Schulz F, et al. A genomic catalog of Earth's microbiomes. Nat Biotechnol. 2021;39:499-509. 
10. Hatzenpichler R, Krukenberg V, Spietz RL, Jay ZJ. Nextgeneration physiology approaches to study microbiome function at single cell level. Nat Rev Microbiol. 2020;18:241-56.

11. Baker BJ, De Anda V, Seitz KW, Dombrowski N, Santoro AE, Lloyd KG. Diversity, ecology and evolution of Archaea. Nat Microbiol. 2020;5:887-900.

12. Abraham WR, Nogales B, Golyshin PN, Pieper DH, Timmis KN. Polychlorinated biphenyl-degrading microbial communities in soils and sediments. Curr Opin Microbiol. 2002;5:246-53.

13. Galbán-Malagón C, Berrojalbiz N, Ojeda M-J, Dachs J. The oceanic biological pump modulates the atmospheric transport of persistent organic pollutants to the Arctic. Nat Commun 2012;3:862

14. Pieper DH. Aerobic degradation of polychlorinated biphenyls. Appl Microbiol Biotechnol. 2005;67:170-91.

15. Chain PSG, Denef VJ, Konstantinidis KT, Vergez LM, Agulló L, Reyes VL, et al. Burkholderia xenovorans LB400 harbors a multireplicon, 9.73-Mbp genome shaped for versatility. Proc Natl Acad Sci USA. 2006;103:15280.

16. Furukawa K, Suenaga H, Goto M. Biphenyl dioxygenases: functional versatilities and directed evolution. J Bacteriol. 2004;186:5189-96.

17. McLeod MP, Warren RL, Hsiao WWL, Araki N, Myhre M, Fernandes C, et al. The complete genome of Rhodococcus sp. RHA1 provides insights into a catabolic powerhouse. Proc Natl Acad Sci USA. 2006;103:15582.

18. Lee TK, Lee J, Sul WJ, Iwai S, Chai BC, Tiedje JM, et al. Novel biphenyl-oxidizing bacteria and dioxygenase genes from a Korean tidal mudflat. Appl Environ Microbiol. 2011;77:3888-91.

19. Sul WJ, Park J, Quensen JF, Rodrigues JLM, Seliger L, Tsoi TV, et al. DNA-stable isotope probing integrated with metagenomics for retrieval of biphenyl dioxygenase genes from polychlorinated biphenyl-contaminated river sediment. Appl Environ Microbiol. 2009;75:5501-6.

20. Uhlik O, Jecna K, Mackova M, Vlcek C, Hroudova M, Demnerova $\mathrm{K}$, et al. Biphenyl-metabolizing bacteria in the rhizosphere of horseradish and bulk soil contaminated by polychlorinated biphenyls as revealed by stable isotope probing. Appl Environ Microbiol. 2009;75:6471.

21. Jiang LF, Luo CL, Zhang DY, Song MK, Sun YT, Zhang G. Biphenyl-Metabolizing microbial community and a functional operon revealed in e-waste-contaminated soil. Environ Sci Technol. 2018;52:8558-67.

22. Tillmann S, Strompl C, Timmis KN, Abraham WR. Stable isotope probing reveals the dominant role of Burkholderia species in aerobic degradation of PCBs. FEMS Microbiol Ecol. 2005;52:207-17.

23. Leigh MB, Pellizari VH, Uhlik O, Sutka R, Rodrigues J, Ostrom $\mathrm{NE}$, et al. Biphenyl-utilizing bacteria and their functional genes in a pine root zone contaminated with polychlorinated biphenyls (PCBs). ISME J. 2007;1:134-48.

24. Chen S-C, Duan G-L, Ding K, Huang F-Y, Zhu Y-G. DNA stable-isotope probing identifies uncultivated members of Pseudonocardia associated with biodegradation of pyrene in agricultural soil. FEMS Microbiol Ecol. 2018;94:fiy026.

25. Neufeld JD, Dumont MG, Vohra J, Murrell JC. Methodological considerations for the use of stable isotope probing in microbial ecology. Micro Ecol. 2007;53:435-42.

26. Neufeld JD, Vohra J, Dumont MG, Lueders T, Manefield M, Friedrich MW, et al. DNA stable-isotope probing. Nat Protoc. 2007;2:860-6.

27. Mohn WW, Westerberg K, Cullen WR, Reimer KJ. Aerobic biodegradation of biphenyl and polychlorinated biphenyls by Arctic soil microorganisms. Appl Environ Microbiol. 1997;63:3378-84.
28. Wagner-Dobler I, Bennasar A, Vancanneyt M, Strompl C, Brummer I, Eichner C, et al. Microcosm enrichment of biphenyldegrading microbial communities from soils and sediments. Appl Environ Microbiol. 1998;64:3014-22.

29. Allen MB. Studies with cyanidium caldarium, an anomalously pigmented chlorophyte. Arch Mikrobiol. 1959;32:270-7.

30. Rabus R, Widdel F. Anaerobic degradation of ethylbenzene and other aromatic hydrocarbons by new denitrifying bacteria. Arch Microbiol. 1995;163:96-103.

31. Zhou J, Bruns MA, Tiedje JM. DNA recovery from soils of diverse composition. Appl Environ Microbiol. 1996;62:316.

32. Pruesse E, Peplies J, Glöckner FO. SINA: accurate highthroughput multiple sequence alignment of ribosomal RNA genes. Bioinformatics 2012;28:1823-9.

33. Quast C, Pruesse E, Yilmaz P, Gerken J, Schweer T, Yarza P, et al. The SILVA ribosomal RNA gene database project: improved data processing and web-based tools. Nucleic Acids Res 2013;41:D590-D6.

34. Ouyang WY, Su JQ, Richnow HH, Adrian L. Identification of dominant sulfamethoxazole-degraders in pig farm-impacted soil by DNA and protein stable isotope probing. Environ Int. 2019;126:118-26.

35. Tischer K, Zeder M, Klug R, Pernthaler J, Schattenhofer M, Harms $\mathrm{H}$, et al. Fluorescence in situ hybridization (CARD-FISH) of microorganisms in hydrocarbon contaminated aquifer sediment samples. Syst Appl Microbiol. 2012;35:526-32.

36. Polerecky L, Adam B, Milucka J, Musat N, Vagner T, Kuypers MMM. Look@NanoSIMS-a tool for the analysis of nanoSIMS data in environmental microbiology. Environ Microbiol. 2012;14:1009-23.

37. Stryhanyuk H, Calabrese F, Kümmel S, Musat F, Richnow HH, Musat N. Calculation of single cell assimilation rates from SIPNanoSIMS-derived isotope ratios: a comprehensive approach. Front Microbiol. 2018;9:2342.

38. Bolger AM, Lohse M, Usadel B. Trimmomatic: a flexible trimmer for Illumina sequence data. Bioinformatics 2014;30:2114-20.

39. Bankevich A, Nurk S, Antipov D, Gurevich AA, Dvorkin M, Kulikov AS, et al. SPAdes: a new genome assembly algorithm and its applications to single-cell sequencing. J Comput Biol. 2012;19:455-77.

40. Kang DD, Li F, Kirton E, Thomas A, Egan R, An H, et al. MetaBAT 2: an adaptive binning algorithm for robust and efficient genome reconstruction from metagenome assemblies. PeerJ 2019;7:e7359-e.

41. Parks DH, Imelfort M, Skennerton CT, Hugenholtz P, Tyson GW. CheckM: assessing the quality of microbial genomes recovered from isolates, single cells, and metagenomes. Genome Res. 2015;25:1043-55.

42. Chaumeil P-A, Mussig AJ, Hugenholtz P, Parks DH. GTDB-Tk: a toolkit to classify genomes with the Genome Taxonomy Database. Bioinformatics 2020;36:1925-7.

43. Stamatakis A. RAxML version 8: a tool for phylogenetic analysis and post-analysis of large phylogenies. Bioinformatics 2014:30:1312-3.

44. Hyatt D, Chen G-L, Locascio PF, Land ML, Larimer FW, Hauser LJ. Prodigal: prokaryotic gene recognition and translation initiation site identification. BMC Bioinforma. 2010;11:119.

45. Kanehisa M, Goto S. KEGG: kyoto encyclopedia of genes and genomes. Nucleic Acids Res. 2000;28:27-30.

46. Finn RD, Bateman A, Clements J, Coggill P, Eberhardt RY, Eddy SR, et al. Pfam: the protein families database. Nucleic Acids Res. 2014;42:D222-D30.

47. Huerta-Cepas J, Szklarczyk D, Heller D, Hernández-Plaza A, Forslund SK, Cook H, et al. eggNOG 5.0: a hierarchical, functionally and phylogenetically annotated orthology resource based 
on 5090 organisms and 2502 viruses. Nucleic Acids Res. 2019;47: D309-D14. (D1)

48. Camacho C, Coulouris G, Avagyan V, Ma N, Papadopoulos J, Bealer K, et al. BLAST+: architecture and applications. BMC Bioinforma. 2009;10:421.

49. Edgar RC. MUSCLE: multiple sequence alignment with high accuracy and high throughput. Nucleic Acids Res. 2004;32:1792-7.

50. Capella-Gutiérrez S, Silla-Martínez JM, Gabaldón T. trimAl: a tool for automated alignment trimming in large-scale phylogenetic analyses. Bioinformatics. 2009;25:1972-3.

51. Budhraja R, Karande S, Ding C, Ullrich MK, Wagner S, Reemtsma $\mathrm{T}$, et al. Characterization of membrane-bound metalloproteins in the anaerobic ammonium-oxidizing bacterium "Candidatus Kuenenia stuttgartiensis" strain CSTR1. Talanta. 2021;223:121711.

52. Craig R, Beavis RC. TANDEM: matching proteins with tandem mass spectra. Bioinformatics. 2004;20:1466-7.

53. Röst HL, Sachsenberg T, Aiche S, Bielow C, Weisser H, Aicheler F, et al. OpenMS: a flexible open-source software platform for mass spectrometry data analysis. Nat Methods. 2016;13:741-8.

54. Sachsenberg T, Herbst F-A, Taubert M, Kermer R, Jehmlich N, von Bergen $\mathrm{M}$, et al. MetaProSIP: automated inference of stable isotope incorporation rates in proteins for functional metaproteomics. J Proteome Res. 2015;14:619-27.

55. Liu J, He XX, Lin XR, Chen WC, Zhou QX, Shu WS, et al. Ecological effects of combined pollution associated with e-waste recycling on the composition and diversity of soil microbial communities. Environ Sci Technol. 2015;49:6438-47.

56. Kumamaru T, Suenaga H, Mitsuoka M, Watanabe T, Furukawa $\mathrm{K}$. Enhanced degradation of polychlorinated biphenyls by directed evolution of biphenyl dioxygenase. Nat Biotechnol. 1998;16:663-6.

57. Garrido-Sanz D, Manzano J, Martín M, Redondo-Nieto M, Rivilla R. Metagenomic analysis of a biphenyl-degrading soil bacterial consortium reveals the metabolic roles of specific populations. Front Microbiol. 2018;9:232.

58. Kikuchi Y, Nagata Y, Ohtsubo Y, Koana T, Takagi M. Pseudomonas fluorescens KKL101, a benzoic acid degrader in a mixed culture that degrades biphenyl and polychlorinated biphenyls. Biosci Biotechnol Biochem. 1995;59:2303-4.

59. Musat N, Halm H, Winterholler B, Hoppe P, Peduzzi S, Hillion F, et al. A single-cell view on the ecophysiology of anaerobic phototrophic bacteria. Proc Natl Acad Sci USA. 2008;105:17861.

60. Calabrese F, Voloshynovska I, Musat F, Thullner M, Schlömann $\mathrm{M}$, Richnow $\mathrm{HH}$, et al. Quantitation and comparison of phenotypic heterogeneity among single cells of monoclonal microbial populations. Front Microbiol. 2019;10:2814.

61. Robertson BR, Button DK, Koch AL. Determination of the biomasses of small bacteria at low concentrations in a mixture of species with forward light scatter measurements by flow cytometry. Appl Environ Microbiol. 1998;64:3900-9.

62. Troussellier M, Bouvy M, Courties C, Dupuy C. Variation of carbon content among bacterial species under starvation condition. Aquat Micro Ecol. 1997;13:113-9.

63. Furukawa K, Miyazaki T. Cloning of a gene cluster encoding biphenyl and chlorobiphenyl degradation in Pseudomonas pseudoalcaligenes. J Bacteriol. 1986;166:392-8.

64. Seeger M, Timmis KN, Hofer B. Conversion of chlorobiphenyls into phenylhexadienoates and benzoates by the enzymes of the upper pathway for polychlorobiphenyl degradation encoded by the bph locus of Pseudomonas sp. strain LB400. Appl Environ Microbiol. 1995;61:2654-8.

65. Chadhain SM, Moritz EM, Kim E, Zylstra GJ. Identification, cloning, and characterization of a multicomponent biphenyl dioxygenase from Sphingobium yanoikuyae B1. J Ind Microbiol Biotechnol. 2007;34:605-13.

66. Hofer B, Backhaus S, Timmis KN. The biphenyl/polychlorinated biphenyl-degradation locus (bph) of Pseudomonas sp. LB400 encodes four additional metabolic enzymes. Gene 1994;144:9-16.

67. Harwood CS, Parales RE. The beta-ketoadipate pathway and the biology of self-identity. Annu Rev Microbiol. 1996;50:553-90.

68. Rather LJ, Knapp B, Haehnel W, Fuchs G. Coenzyme Adependent aerobic metabolism of benzoate via epoxide formation. J Biol Chem. 2010;285:20615-24.

69. Stegen JC, Fredrickson JK, Wilkins MJ, Konopka AE, Nelson WC, Arntzen EV, et al. Groundwater-surface water mixing shifts ecological assembly processes and stimulates organic carbon turnover. Nat Commun. 2016;7:1-12.

70. Corteselli EM, Aitken MD, Singleton DR. Rugosibacter aromaticivorans gen. nov., sp. nov., a bacterium within the family Rhodocyclaceae, isolated from contaminated soil, capable of degrading aromatic compounds. Int J Syst Evol Microbiol 2017;67:311-8.

71. Fernandez H, Prandoni N, Fernandez-Pascual M, Fajardo S, Morcillo C, Diaz E, et al. Azoarcus sp. CIB, an anaerobic biodegrader of aromatic compounds shows an endophytic lifestyle. PLoS ONE. 2014;9:e110771.

72. Iwai S, Johnson TA, Chai BL, Hashsham SA, Tiedje JM. Comparison of the specificities and efficacies of primers for aromatic dioxygenase gene analysis of environmental samples. Appl Environ Microbiol. 2011;77:3551-7.

73. Top EM, Springael D. The role of mobile genetic elements in bacterial adaptation to xenobiotic organic compounds. Curr Opin Biotechnol. 2003;14:262-9.

74. Dombrowski N, Donaho JA, Gutierrez T, Seitz KW, Teske AP, Baker BJ. Reconstructing metabolic pathways of hydrocarbondegrading bacteria from the Deepwater Horizon oil spill. Nat Microbiol. 2016;1:1-7.

75. de Lorenzo V. Systems biology approaches to bioremediation. Curr Opin Biotechnol. 2008;19:579-89.

76. Rabus R, Wöhlbrand L, Thies D, Meyer M, Reinhold-Hurek B, Kämpfer P. Aromatoleum gen. nov., a novel genus accommodating the phylogenetic lineage including Azoarcus evansii and related species, and proposal of Aromatoleum aromaticum sp. nov., Aromatoleum petrolei sp. nov., Aromatoleum bremense sp. nov., Aromatoleum toluolicum sp. nov. and Aromatoleum diolicum sp. nov. Int J Syst Evol Microbiol. 2019;69:982-97.

77. Vogt C, Richnow HH. Bioremediation via in situ microbial degradation of organic pollutants. Adv Biochem Engin/Biotechnol. 2014;142:123-46.

78. Cunningham JA, Rahme H, Hopkins GD, Lebron C, Reinhard M. Enhanced in situ bioremediation of BTEX-contaminated groundwater by combined injection of nitrate and sulfate. Environ Sci Technol. 2001;35:1663-70.

79. Mondello FJ, Turcich MP, Lobos JH, Erickson BD. Identification and modification of biphenyl dioxygenase sequences that determine the specificity of polychlorinated biphenyl degradation. Appl Environ Microbiol. 1997;63:3096-103.

80. Gomez-Gil L, Kumar P, Barriault D, Bolin JT, Sylvestre M, Eltis LD. Characterization of biphenyl dioxygenase of Pandoraea pnomenusa $\mathrm{B}-356$ as a potent polychlorinated biphenyl-degrading enzyme. J Bacteriol. 2007;189:5705-15. 